\title{
Correlation between deletion patterns of SMN and NAIP genes and the clinical features of spinal muscular atrophy in Indian patients
}

\author{
Rashna S. Dastur, Pradnya S. Gaitonde, Satish V. Khadilkar*, Vrajesh P. Udani`*, \\ Jayshree J. Nadkarni \\ Department of Neuropathology and Applied Biology, Medical Research Centre, *Department of Neurology, Bombay Hospital, Mumbai, \\ ${ }^{\star *}$ Department of Neurology, P. D. Hinduja National Hospital and Medical Research Centre, Mumbai, India
}

Background: Spinal muscular atrophy (SMA) is an autosomal recessive neuromuscular disorder involving degeneration of anterior horn cells of spinal cord resulting in progressive muscle weakness and atrophy. Aims: The molecular analysis of two marker genes for spinal muscular atrophy (SMA) i.e., the survival motor neuron gene (SMN) and the neuronal apoptosis inhibitory protein gene (NAIP) was conducted in 39 Indian patients with clinical symptoms of SMA. Out of these, 28 showed homozygous deletions and the phenotypic features of these SMA patients were compared with the corresponding genotypes. Settings: A tertiary care teaching Hospital. Design: This is a prospective hospital based study. Materials and Methods: Polymerase chain reaction (PCR) combined with restriction fragment length polymorphism (RFLP) was used to detect the deletion of exon 7 and exon 8 of SMN1 gene, as well as multiplex PCR for exon 5 and 13 of NAIP gene. Results: Exons 7 and 8 of SMN and NAIP (exon 5) were homozygously deleted in $73 \%$ of SMA I and $27 \%$ of SMA II patients. SMN exon 7 and 8 deletions without NAIP deletions were seen in $27 \%$ of type I SMA and $46 \%$ of SMA type II patients. Two patients of type III SMA showed single deletion of SMN exon 7 along with $27 \%$ of SMA type II patients. Conclusion: With the advent of molecular biology techniques, SMN gene deletion studies have become the first line of investigation for confirmation of a clinical diagnosis of SMA. The findings of homozygous deletions of exons 7 and/or 8 of SMN1 gene confirms the diagnosis of SMA, even in patients with atypical clinical features. Deletions of NAIP gene were mainly seen in severely affected patients, hence is useful for predicting the prognosis.

Key words: Neuronal apoptotic inhibitory protein gene, spinal muscular atrophy, survival motor neuron gene

\section{Introduction}

Spinal muscular atrophies (SMA) are a clinically and genetically heterogeneous group of disorders characterized by primary degeneration of anterior horn cells of the spinal cord and brain stem nuclei causing progressive muscle weakness. ${ }^{[1]}$

SMA is one of the most common lethal autosomal recessive disorder, with the childhood onset form of SMA between 1 in 6000 and 1 in 10,000 live births. ${ }^{[2,3]}$ The three types of SMAs present with diverse symptoms and differ in age of onset, mode of inheritance, distribution of muscle weakness and progression of symptoms. ${ }^{[2]}$

SMA of all types is associated with homozygous mutations in the Survival Motor Neuron gene (SMN1 gene) located at the telomeric end of chromosome region $5 q 13 .^{[4,5]}$ A large inverted repeat at the centromeric region of $5 q 13$ consists of homologous gene SMN2. SMN1 and SMN2 differ in exons 7, 8 and 6 by only one base pair each and in five introns. ${ }^{[2,6]}$

The presence of a $\mathrm{C}->\mathrm{T}$ transition at codon 280 within exon 7 of SMN2 causes disruption of an exonic splice enhancer. ${ }^{[7]}$ This leads to abnormal splicing which produces unstable truncated protein. ${ }^{[8]}$ SMN2 does produce a small amount of functional fulllength protein but the majority of the full-length protein is produced by SMN1. ${ }^{[9]}$

Another gene, the neuronal apoptosis inhibitory protein gene (NAIP), located on the same chromosomal region of 5 q 13, was found to be deleted in SMA patients. ${ }^{[1,10]}$ The NAIP has been postulated to have neuroprotective effect and acts as a negative regulator of motor neuron apoptosis. ${ }^{[10]}$ It was suggested that the absence of the full-length NAIP gene is necessary but not sufficient to produce SMA. ${ }^{[10]}$

The purpose of this study was to confirm the clinical diagnosis of SMA patients and to correlate the frequency of deletions within SMN and NAIP genes. The study mainly concentrates on the 
pattern of gene deletions seen in three different types of SMA patients and their correlation with the clinical severity. It does not attempt to determine the prevalence of deletions in clinically suspected SMA patients.

\section{Materials and Methods}

A total of 49 blood samples received between the period of September 2004 and December 2005, all from the Indian population, were studied for SMN1 and NAIP gene deletions. The 39 patients included in the study were strongly suspected of SMA after a full clinical evaluation. Ten samples from non-SMLA patients were also run as controls.

\section{Detection of SMN1 and NAIP gene deletions by PCR- RFLP method}

Genomic DNA was extracted using sigma NA 2020 kit from peripheral blood (collected in EDTA bulbs). Polymerase chain reaction (PCR) amplification of SMN exons 7 and 8 and NAIP exons 5 and 13 was carried out in a total volume of $50 \mu \mathrm{l}$ using Hot Star Taq Master Mix (QLAGEN) for SMN ( 7 and 8) gene and QLAGEN multiplex PCR kit for NAIP exons 5 and 13. The Hot Star Taq used in all the PCR reactions was activated at $95^{\circ} \mathrm{C}$ for 15 mins before the cycles commenced.

\section{SMNgene}

Exon 7 was amplified with intron 6 primer R111 (2 $\mu \mathrm{M})$ and mismatch primer X7-Dra $(2 \mu \mathrm{M})$ in 35 cycles of 1 min at $94^{\circ} \mathrm{C}, 1$ $\min$ at $55^{\circ} \mathrm{C}$ and $1 \mathrm{~min}$ at $72^{\circ} \mathrm{C} \cdot{ }^{[6,11]} \mathrm{PCR}$ products $(25 \mu \mathrm{l})$ along with 1 x enzyme buffer SM $(25 \mu \mathrm{l})$ were subsequently digested to completeness with restriction enzyme Dra I (2 units) (Sigma) [Table 1].

By using a mismatch primer (X7-Dra) on the 3' end of exon 7, a $\mathrm{G}$ to A change is introduced at positive 875 of the cDNA. This change creates a Dra I site (TTTAAA). The third T nucleotide of the sequence is present only in the SMN 2 gene and is a $\mathrm{C}$ in the SMN 1 gene, thus the enzyme cuts only the SMN 2 amplified PCR product. ${ }^{[6,11]}$ Hence, after digestion two bands are seen, one at $188 \mathrm{bp}$ (indicating SMN 1) and the other at $176 \mathrm{bp}$ (representing SMN 2) as gene amplified products.

For exon 8, DNA was amplified with primers 541C960 and $541 \mathrm{C} 1120$ ( $2 \mu \mathrm{M}$ each), with the same PCR conditions, except for an annealing temperature of $59^{\circ} \mathrm{C}$ instead of $55^{\circ} \mathrm{C} \cdot{ }^{[6,11]} \mathrm{PCR}$ products $(25 \mu \mathrm{l})$ were subsequently digested with restriction enzyme Dde I (2 units).

Table 1: Classification of spinal muscular atrophies. ${ }^{[13]}$

\begin{tabular}{|c|c|c|c|}
\hline Designation & $\begin{array}{l}\text { Symptom } \\
\text { onset }\end{array}$ & Course & Survival \\
\hline $\begin{array}{l}\text { Type I (severe) } \\
\text { Werdnig-Hoffmann }\end{array}$ & 0-6 months & Never sits & $<2$ years \\
\hline $\begin{array}{l}\text { Type II } \\
\text { (intermediate- chronic) }\end{array}$ & 6-18 months & Never stands & $>2$ years \\
\hline $\begin{array}{l}\text { Type III (mild) } \\
\text { Kugelberg - Welander }\end{array}$ & $>12$ months & Stands alone & Adult \\
\hline
\end{tabular}

The nucleotide in exon 8 which differs between SMN 1 and SMN 2 genes is $\mathrm{G}>\mathrm{A}$. The $\mathrm{A}$ in the SMN 2 gene (located at position 1155 of the cDNA) creates a Dde I site which will digest the amplified DNA into two products of $122 \mathrm{bp}$ and $78 \mathrm{bp} .^{[6,11]}$

The exon 8 of SMN1 gene (200 bp) does not contain any Dde $\mathrm{I}$, site hence it will not be cut and will remain as $200 \mathrm{bp} .^{[2]}$

\section{NAIP exon 5}

For NAIP, exon 5 and 13 (exon 13 taken as positive control), a multiplex reaction was carried out for 30 cycles of $94^{\circ} \mathrm{C}$ for $1 \mathrm{~min}$, $60^{\circ} \mathrm{C}$ for $1 \mathrm{~min}$ and $72^{\circ} \mathrm{C}$ for $1 \mathrm{~min}$ using primers 1864 and 1863 for exon 5 and primers 1258 and 1343 for exon 13. ${ }^{[10,12]}$

PCR products from both SMN gene products and NAIP were run on $2 \%$ agarose high fidelity gel (Sigma) stained with ethidium bromide in 1x TBE buffer and visualised under UV transilluminator and gel documentation system (Vilber Lourmat - France).

SMA was classically subdivided into three types based on age of onset and clinical severity. The standard ISMAC (International SMA consortium) classification for SMA given in Table 1 was used for this study. ${ }^{[13]}$

\section{Results}

Molecular analysis using PCR-RFLP assay, on 39 clinically suspected cases of SMA revealed 28 patients with homozygous deletions in SMN1 or/and NAIP genes [Table 2]. Out of these 28 SMA patients showing deletions, the maximum number (54\%) were of Type II followed by Type I (39\%) and only 7\% were Type III. The classification into different types was based on the ISMAC.

SMA I: Eleven SMA I patients showed homozygous deletions for SMN1 gene and/or NAIP gene [Table 2]. Their ages ranged between 1.5 months to 2 years. Ten patients were between 1.5 months to 10 months; only one patient was age two years, who died shortly. All these patients were unable to sit or hold head and were floppy infants. EMG was possible only in four of the 11 patients and showed AHC (anterior horn cell disease).

The deletion analysis for SMN1 and NAIP genes of these patients showed 73\% to have homozygous deletions of both SMN1 gene (exons 7 and 8) and NAIP gene (exon 5) (Figure 1 lane 4c, $7 \mathrm{c}$ and 10c), while $27 \%$ showed deletions of exons 7 and 8 of only the SMN1 gene. None of the patients of SMA type I revealed a deletion of only exon 7 of the SMN gene. It was observed in these 11 patients that a severe phenotype is manifested mainly when deletions occur in both exon 7 and exon 8 of SMN and/or NAIP gene [Table 2].

SMA II: Fifteen patients showing homozygous deletions were classified as SMA II, which is the largest group in our study (54\%). Age of patients ranged from one year to 20 years. All patients could not walk and $93 \%$ of them showed wasting and areflexia of the lower limbs. Tongue fasciculations were seen in three of the patients, out of which two were sibs (brother and sister). EMG was done in only five of the 15 patients and showed AHC (anterior horn cell) disorder. 
Table 2: Genotype phenotype correlation of 28 spinal muscular atrophy patients

\begin{tabular}{|c|c|c|c|}
\hline TOTAL: 28 & SMA I (11) & SMA II (15) & SMA III (2) \\
\hline Deletion of SMN 1 - Ex 7 and 8; & $8 / 11$ & $4 / 15$ & \\
\hline \multirow[t]{9}{*}{ NAIP-Ex 5} & 6 males $/ 2$ females & 3 males $/ 1$ female & \\
\hline & Age range: $1.5 \mathrm{mts}-2 \mathrm{yrs}$ & Age range: $3-20$ yrs & \\
\hline & Could not sit or hold head: $8 / 8$ & Could not walk: $4 / 4$ & \\
\hline & Floppy infant: $8 / 8$ & Delayed milestones: $1 / 4$ & \\
\hline & Areflexia: $7 / 8$ & Areflexia of lower limbs: $3 / 4$ & \\
\hline & Prox. and dist. weakness in all 4 limbs: $8 / 8$ & Wasting of lower limbs: $3 / 4$ & \\
\hline & Respiratory discomfort: $8 / 8$ & Tongue fasciculation: $2 / 4$ & \\
\hline & EMG- $A H C: 2 / 8$ & EMG-AHC: $2 / 3$ & \\
\hline & Age of death $2 \mathrm{mts}-2$ yrs: $6 / 8$ & & \\
\hline \multirow[t]{10}{*}{ Deletion of SMN 1 - Ex 7 and 8} & $3 / 11$ & $7 / 15$ & \\
\hline & 3 males $/ 0$ females & 2 males $/ 5$ females & \\
\hline & Age range: $2 \mathrm{mts}-11 \mathrm{mts}$ & Age range: 2 yrs - 5 yrs & \\
\hline & Could not sit or hold head: $3 / 3$ & Could not walk: $7 / 7$ & \\
\hline & Floppy infant: $3 / 3$ & Areflexia of lower limbs: $7 / 7$ & \\
\hline & Areflexia: $3 / 3$ & Wasting of lower limbs: $7 / 7$ & \\
\hline & Prox. and dist. weakness in all 4 limbs: $3 / 3$ & Tongue fasciculation: $1 / 7$ & \\
\hline & Respiratory discomfort: $3 / 3$ & EMG- AHC: $2 / 7$ & \\
\hline & EMG- AHC: $2 / 3$ & & \\
\hline & Age of death $2-3$ mts: $2 / 3$ & & \\
\hline \multirow[t]{7}{*}{ Deletion of SMN 1 - Ex 7} & & $4 / 15$ & $2 / 2$ \\
\hline & & 3 males $/ 1$ female & 1 male / 1 female \\
\hline & & Age range: $1 \mathrm{yr}-9 \mathrm{yrs}$ & Age range: $14-24$ yrs \\
\hline & & Could not walk: $4 / 4$ & Could walk: $2 / 2$ \\
\hline & & Delayed milestones: $4 / 4$ & Proximal leg weakness: $2 / 2$ \\
\hline & & Areflexia of lower limbs: $4 / 4$ & Slowly progressive: $2 / 2$ \\
\hline & & $\begin{array}{l}\text { Wasting of lower limbs: } 4 / 4 \\
\text { EMG-AHC: } 1 / 4\end{array}$ & \\
\hline
\end{tabular}

${ }^{*}$ AHC-Anterior horn cell, SMA-Spinal muscular atrophies

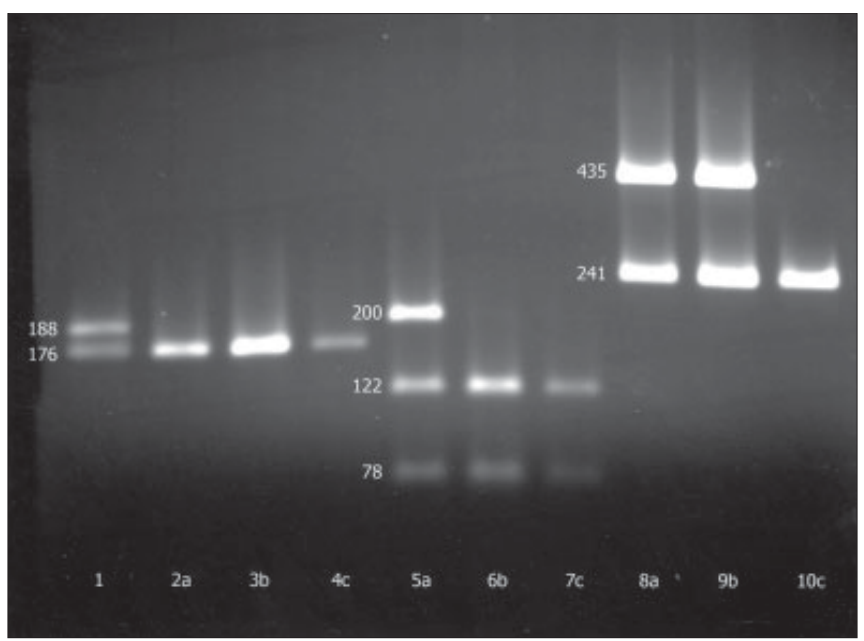

Figure 1: Agarose gel electrophoresis of PCR amplified products of SMA patients for SMN exon 7 (after Dra I digestion) (row 1 to 4), exon 8 (after Dde I digestion) (row 5 to 7) and NAIP exon 5 and 13 (row 8 to 10). Lane 1: SMN exon 7 control showing no deletion of exon 7 of SMN 1. Patient ' $a$ ': lanes $(2,5$ and 8$)$ showing only SMN1 exon 7 deletion (2a). Patient ' $b$ ': lanes $(3,6$ and 9) showing exons 7 and 8 of SMN 1 gene deleted. Patient ' $c$ ': lanes $(4,7$ and 10) showing deletions of SMN1 exon 7 and 8 and NAIP exon 5

Forty-six percent of type II patients showed both exons 7 and 8 of SMN1 gene deletion, (Figure 1 lane 3b, 6b and 9b) while about $27 \%$ showed deletion of only exon 7 of SMN gene. NAIP gene (exon 5) along with SMN1 (exon 7 and 8) was deleted in $27 \%$ of SMA II patients. Two sets of siblings (brother and sister) with SMA type II were studied.

One pair of sibs aged 12 and 20 years showed deletions in both SMN1 (exons 7 and 8) and NAIP (exon 5). Both brother and sister first manifested with symptoms at age six months. Both had an insidious onset of weakness of the limbs and trunk and over the next few years regressed in their motor milestones. They were unable to stand. On clinical examination they showed tongue fasciculation, areflexia and marked proximal muscle weakness in both upper and lower limbs. Their EMG confirmed anterior horn cell disease. Their elder sister (25 years) was normal and showed no gene deletions.

The other pair of sibs also brother and sister aged two years and five years respectively showed deletions in both exon 7 and 8 of SMN1 gene only.

SMA III: Only two patients from a group of 28 , aged 14 years (male) and 24 years (female) were of SMA type III. Both these patients had slowly progressive weakness of lower limbs. One of the patients, a 24 year-old female, initially showed difficulty in climbing stairs at the age of eight years. She had a very slowly progressive proximal leg weakness and was unable to do heavy work although still able to walk and climb unaided. Her EMG indicated AHC disease (EMG was not done on the other patient). Both these patients showed SMN1 gene deletion of exon 7 only (Figure 1 lane 2a, 5a and 8a).

The remaining 11 who failed to show any deletion for SMN gene ranged from age 14 days to 38 years. Six out of 11 were adults between the ages of 10 to 38 years with late onset of symptoms. Three patients whose age ranged between 14 days to 7 months were born as "floppy infants" and had a differential diagnosis between SMA I, congenital myopathy or hypotonic cerebral palsy. One, 1 year-old patient showed strong clinical features of SMA but failed to show any deletion in either SMN1 
or NAIP genes. The remaining patient aged 1.5 years showed clinical symptoms such as difficulty in walking, areflexia but failed to show any deletion. Further molecular studies on these patients were not possible hence it was difficult to calculate the total frequency of deletions seen in this group of patients.

\section{Discussion}

Among all the candidate genes, SMN1 is believed to be the primary SMA disease-causing gene. The finding of homozygous deletions of exons 7 and/or 8 of SMN1 patients with consistent clinical features is generally considered to be diagnostic of SMA. ${ }^{[14]}$

Our study concentrates on genotype phenotype correlation of patients showing homozygous deletions in SMN1 gene or both SMN1 and NAIP gene. The extent of deletions i.e., SMN1 gene exons 7 and 8 and NAIP gene exon 5 seen in our 28 patients were studied along with the clinical history and symptoms [Table 2]. Though there was an overlap in deletions seen and the severity and type of SMA, on the whole it was observed that majority of patients showing more deletions resulted in a severe phenotype. This was apparent in our 11 type I patients where 73\% showed SMN1 gene exon 7 and 8 as well as NAIP gene deletion. While $27 \%$ of SMA II patients had all three deletions, no patients of SMA III (mild phenotype) showed all three or even two deletions [Table 2].

NAIP deletion alone, without SMN I being deleted, was not seen in any of our patients including the parents of the two siblings studied. This is contrary to the results of Japanese patients where two unaffected mothers of patients with NAIP and SMN1 deletions showed deletions of only NAIP gene. ${ }^{[15]}$ Also no differences were noted in the age of onset/duration of survival in type I patients, regardless of whether the NAIP gene was deleted or not [Table 2]. In fact one of our patients lacking NAIP was two years old (who died shortly), which is consistent with a report by Taylor et al. ${ }^{[16]}$ Another report from Japan showed that, in type I patients lacking NAIP gene, respiratory function deterioration is more rapid than those retaining NAIP gene. ${ }^{[17]}$ However, this was not the case in our patients of type I SMA, where all 11 patients regardless of NAIP deletion showed respiratory dysfunction [Table $2]$. Inspite of this it was seen that a greater percent showed deletions in both genes i.e., $73 \%$ of our type I patients showed NAIP gene deletions along with SMN1 exons 7 and 8, with a resultant more severe phenotype.

NAIP was deleted (along with SMN1 exons 7 and 8) in four of the 15 patients with SMA II, though the age range of these patients was between 3-20 years [Table 2]. It should be noted that the two older patients i.e., 12 and 20 years (showing all three deletions) were siblings who manifested the symptoms at the age of 6 months, but came for deletion studies at age 12 and 20 years respectively. Though the survival age of one of the patients is 20 years, it is not unusual as $70 \%$ of SMA II patients are found to survive till the age of 25 years. ${ }^{[18]}$ The remaining type II patients were below the age of five years, except for one nine year-old showing SMN1 exon 7 deletion only.

The total frequency of deletions seen in our 39 patients was not calculated as further molecular conformation (i.e., Point mutations, gene copy number, sequencing etc.) of the remaining 11 patients who did not show deletions, was not available. Though five patients were strongly suggestive of SMA on clinical examination and EMG, it was not possible to determine with molecular genetic studies whether these patients had some other type of mutation e.g., point mutation or if any other gene was deleted. Another group from India, have shown a lower gene deletion frequency in the SMN and NAIP genes in Indian patients and have suggested that these may be mutations in other genes or a population variation. This will need further study. ${ }^{[19]}$

EMG studies could not be carried out in all the patients (only seven out of 28 patients) as when the patient was clinically suspected of SMA, the deletion studies were done first, which often made the EMG redundant. Also, EMG studies are difficult in infants.

The role of NAIP gene in the pathogenesis of SMA is still not very clear. However, our study of 28 patients does indicate that NAIP gene can be a predictive marker of SMA prognosis as reported elsewhere. ${ }^{[10,15,17,20-22]}$ Several studies suggest that NAIP gene exerts effects on differentiation and survival of neuronal cells including the motor neurons. ${ }^{[17]}$ Further studies will be necessary to clarify its exact functional role. On the other hand, SMN2 copy number has been well established as a modifying factor of clinical severity. A higher number of SMN2 copies are observed in type II or type III SMA patients, than in type I patients. ${ }^{[23-25]}$ Hence, copy number of SMN2 gene compensates for the lack of SMN1 gene thereby influencing the severity of SMA.

Campbell et al reported the presence of NAIP gene and an increase of SMN2 copy number in type II or III patients. ${ }^{[24}$ Hence, they concluded that deletion of NAIP gene is often accompanied by a decrease in total copy number of SMN genes in type I SMA and the presence of NAIP gene by an increase of SMN2 copy number or retention of total copy number of SMN genes in type II or III patients. ${ }^{[24]}$

The PCR based test used in this study is a rapid sensitive cost effective and spares the patient (mostly children) the need for invasive diagnostic procedure such as a muscle biopsy. DNA testing has become the primary investigation for confirmation of clinical diagnosis of SMA. The only limitations of this method are in about $5 \%$ of cases where no deletions are seen in a patient highly suggestive of SMA. In such cases, further studies on gene dosage analysis to determine the copy number of SMN1 gene can be done. ${ }^{[14]}$ This analysis is also particularly applicable for prenatal diagnosis. As SMA is an autosomal recessive disorder, the recurrence risk is $25 \%$ in every pregnancy. ${ }^{[14]}$

PCR based assay for determining the presence or absence of SMN1 is not quantitative and therefore cannot identify SMA carriers, for which quantitative PCR is mandatory. ${ }^{[25,26]}$

Comprehensive SMA testing including SMA deletion analysis, 
linkage analysis and SMA carrier testing offers the most complete evaluation of SMA patients and their families.

\section{References}

1. Tsao B, Armon C. Spinal muscular atrophy. e medicine, [updated 2003 Nov 13][cited 2004 Mar 22][about 42p]. Available from http://www.emedicine.com/ Neuro/topic631.htm.

2. Chen L, Carter A, Kant J. Final diagnosis - Spinal muscular atrophy. [cited 2004 July 7] [about 2p]. Available from http//path.upmc.edu/cases/cases382/dx.html.

Saugier-Veber P, Drouot N, Lefebvre S, Charbonnier F, Vial E, Munnich A, et al. Detection of heterozygous SMN1 deletions in SMA families using a single fluorescent multiplex PCR method. .J Med Genet 2001;38:240-3.

4. Brzustowicz LM, Lehner T, Castilla LH, Penchaszadeh GK, Wilhelmsen KC, Daniels $\mathrm{R}$, et al. Genetic mapping of chronic childhood-onset spinal muscular atrophy to chromosome 5q11.2-13.3. Nature 1990;344:540-1.

5. Melki J, Abdelhak S, Sheth P, Bachelot MF, Burlet P, Marcadet A, et al. Gene for chronic proximal spinal muscular atrophies maps to chromosome $5 q$. Nature 1990;44:767-8.

6. Lefebvre S, Burglen L, Reboullet S, Clermont O, Burlet P, Viollet L, et al. Identification and characterization of a spinal muscular atrophy - determining gene. Cell $1995 ; 80: 155-65$

7. Monani UR, Lorson CL, Parsons DW, Prior TW, Androphy EJ, Burghes AH, et al. A single nucleotide difference that alters splicing patterns distinguishes the SMA gene SMN 1 from the copy gene SMN2. Hum Mol Genet 1999;8:1177-83.

8. Nicole S, Diaz CC, Frugier T, Melki J. Spinal muscular atrophy: Recent advances and future prospects. Muscle Nerve 2002;26:4-13.

9. Anderson K, Talbot K. Spinal muscular atrophies reveal motor neuron vulnerability to defects in ribonucleoprotein handling. Curr Opin Neurol 2003;16:595-9.

10. Roy N, Mahadevan MS, Mclean M, Shutler G, Yaraghi Z, Farahani R, et al. The gene for neuronal apoptosis inhibitory protein is partially deleted in individuals with spinal muscular atrophy. Cell 1995;80:167-78.

11. van der Steege G, Grootscholten PM, van der Vlies P, Draaijers TG, Osinga J, Cobben .JM, et al. PCR-based DNA test to confirm clinical diagnosis of autosomal recessive spinal muscular atrophy. Lancet 1995;345:985-6.

12. Stewart H, Wallace A, McGaughran J, Mountford R, Kingston H. Molecular diagnosis of spinal muscular atrophy. Arch Dis Child 1998;78:531-5.

13. Munsat TL. The Spinal Muscular Atrophies. In: Current Neurology. Mosby- year Book Inc: 1994 p. 55 - 71 .

14. Biros I, Forrest S. Spinal muscular atrophy: Untangling the knot? J Med Genet
$1999 ; 36: 1-8$

15. Saitoh M, Sakakihara Y, Kobavashi S, Havashi Y, Yanagisawa M. Correlation between deletion patterns of SMN and NAIP genes and the clinical features of spinal muscular atrophy in Japanese patients. Acta Paediatr Jpn 1997;39:584-9

16. Taylor .JE, Thomas NH, Lewis CM, Abbs S.J, Rodrigues NR, Davies KE, et al Correlation of SMNt and SMNe gene copy number with age of onset and survival in spinal muscular atrophy. Eur J Hum Genet 1998;6:467-74

17. Akutsu T, Nishio H, Sumino K, Takeshima Y, Tsuneishi S, Wada H, et al. Molecular Geneties of Spinal Muscular Atrophy: Contribution of the NAIP gene to Clinica Severity. Kobe .J Med Sci 2002;48:25-31.

18. Prior TW, Russman BS. Spinal muscular atrophy - Gene Reviews. Washington: University of Washington 2004[updated 2004 July 15] [cited 2004 Aug 24] [about 21p]. Available from http://www.geneclinies.org/profiles/sma/details.html.

19. Kesari A, Misra UK, Kalita .J, Mishra VN, Patil S.J, Phadke SR, et al. Study of survival of motor neuron (SMN) and neuronal apoptosis inhibitory protein (NAIP) gene deletions in SMA patients. J Neurol 2005;252:667-71.

20. Idris MM, Chandak GR. Genetic analysis of spinal muscular atrophy in the Indian population. [short report on the internet][cited $2006 \mathrm{Feb} 11]$ [about 2p]. Available from http://www.med.miami.edu/MNBWS/Chandak.html

21. Ma S, Yuan L, Liu T, Yang T, Zhou W, Wu H. Survival motor neuron gene and neuronal apoptosis inhibitory protein gene deletion in patients with spinal muscular atrophy (article in Chinese). Zhongguo Yi Xue KeXue YuanXue Bao $2000 ; 22: 551-4$

22. Kesari A, Idris MM, Chandak GR, Mittal B. Genotype-phenotype correlation of SMN locus genes in spinal muscular atrophy patients from India. Exptl Mol Med $2005 ; 37: 147-54$

23. Yamashita M, Nishio H, Harada Y, Matsuo M, Yamamoto T. Significant increase in the number of the SMN2 gene copies in an adult-onset type III spinal muscular atrophy. Patient with homozygous deletion of the NAIP gene. Eur Neurol 2004;52:101-6.

24. Campbell L, Potter A, Ignatius J, Dubowitz V, Davies K. Genomic variation and gene conversion in spinal muscular atrophy: Implication for disease process and clinical phenotype. Am .J Hum Genet 1997;61:40-50.

25. Feldkotter M, Schwarzer V, Wirth R, Wienker T, Wirth B. Quantitative analyses of SMN1 and SMN2 based on Real-Time Light Cycler PCR: Fast and highly reliable carrier testing and prediction of severity of spinal muscular atrophy. Am .J Hum Genet 2002;70:358-68

26. Ogino S, Gao S, Leonard DG, Paessler M, Wilson RB. Inverse correlation between SMN1 and SMN2 copy numbers: Evidence for gene conversion from SMN2 to SMN1. Eur .J Hum Genet 2003;11:275-7.

Accepted on 27-07-2006

\section{Author Help: Reference checking facility}

The manuscript system (www.journalonweb.com) allows the authors to check and verify the accuracy and style of references. The tool checks the references with PubMed as per a predefined style. Authors are encouraged to use this facility before submitting articles to the journal.

- The style as well as bibliographic elements should be $100 \%$ accurate to get the references verified from the system. A single spelling error or addition of issue number / month of publication will lead to error to verifying the reference.

- Example of a correct style

Sheahan P, O'leary G, Lee G, Fitzgibbon J. Cystic cervical metastases: Incidence and diagnosis using fine needle aspiration biopsy. Otolaryngol Head Neck Surg 2002;127:294-8.

- Only the references from journals indexed in PubMed would be checked.

- $\quad$ Enter each reference in new line, without a serial number.

- $\quad$ Add up to a maximum 15 reference at time.

- If the reference is correct for its bibliographic elements and punctuations, it will be shown as CORRECT and a link to the correct article in PubMed will be given.

- If any of the bibliographic elements are missing, incorrect or extra (such as issue number), it will be shown as INCORRECT and link to possible articles in PubMed will be given. 